\title{
Micropollutant-loaded powdered activated carbon released from waste water treatment plants: a risk for sediment-dwelling organisms?
}

\author{
Marion Woermann ${ }^{*}$, Julios Armand Kontchou ${ }^{\dagger}$ and Bernd Sures (i)
}

\begin{abstract}
Background: In order to protect aquatic environments and to reduce the presence of micropollutants in the global water cycle, wastewater treatment plants (WWTPs) often implement an additional treatment step. One of the most effective measures is the use of powdered activated carbon (PAC) as an adsorbent for micropollutants. This method provides sufficient elimination rates for several micropollutants and has been successfully employed in many WWTPs. Despite this success, there might be a drawback as the retention of the PAC in the WWTP can be challenging and losses of micropollutant-loaded PAC into the aquatic environment may occur. Upon emission, micropollutant-loaded PAC is expected to settle to the benthic zone of receiving waters, where sediment-dwelling organisms may ingest these particles. Therefore, the present study investigated possible adverse effects of micropollutant-loaded PAC from a WWTP as compared to unloaded (native) and diclofenac-loaded PAC on the sediment-dwelling annelid Lumbriculus variegatus.
\end{abstract}

Results: Native PAC induced the strongest effects on growth (measured as biomass) and reproduction of the annelids. The corresponding medium effective concentrations $\left(E_{50}\right)$ were $1.7 \mathrm{~g} / \mathrm{kg}$ and $1.8 \mathrm{~g} / \mathrm{kg}$, respectively. Diclofenacloaded PAC showed lower effects with an $\mathrm{EC}_{50}$ of $2.5 \mathrm{~g} / \mathrm{kg}$ for growth and $\mathrm{EC}_{50}$ of $3.0 \mathrm{~g} / \mathrm{kg}$ for reproduction. Although tested at the same concentrations, the micropollutant-loaded PAC from the WWTP did not lead to obvious negative effects on the endpoints investigated for $L$. variegatus and only a slight trend of a reduced growth was detected.

Conclusion: We did not detect harmful effects on L. variegatus caused by the presence of MP-loaded PAC from a WWTP which gives an auspicious perspective for PAC as an advanced treatment option.

Keywords: Oligochaete, Environmental impact, Advanced wastewater treatment, Lumbriculus variegatus, Sediment toxicity

\section{Background}

The occurrence of micropollutants (MPs) in aquatic environments is of growing concern worldwide due to their persistence and their potential harmful effects on aquatic organisms. Individually, as well as in mixtures,

\footnotetext{
*Correspondence: bernd.sures@uni-due.de

${ }^{\dagger}$ Marion Woermann and Julios Armand Kontchou contributed equally to this work

Aquatic Ecology and Centre for Water and Environmental Research (ZWU), University Duisburg-Essen, Universitätsstrasse 5, 45141 Essen, Germany
}

MPs exhibit a variety of toxic effects on organisms as well as on communities of freshwater biota [1-3]. MPs comprise mainly pharmaceuticals, personal care products, hormones, surfactants, industrial chemicals and pesticides [4] and are primarily discharged into surface waters by wastewater treatment plants (WWTPs) [5]. In order to reduce the release of these MPs into freshwater bodies, many WWTPs are currently upgrading their treatment protocols by applying additional treatment steps [6]. There are various possible options and the two techniques that are mainly applied are advanced oxidation processes (i.e., ozonation) or adsorption on activated 
carbon (AC) [7]. Application of ozonation is intended to mineralize MP and thereby to reduce their toxic potential. However, several MPs cannot be completely degraded which can result into undesired transformation products that can exhibit even a higher toxicity than the original MP [7-9]. The advantage in using adsorption techniques for MP elimination is the physical removal of MPs from the wastewater instead of their degradation [6, 10].

The use of powdered activated carbon (PAC) as an adsorbent has already been successfully implemented in several WWTPs [11-14]. PAC can be applied in a contact reactor after the biological treatment followed by its separation with sedimentation and filtration $[10,12$, 15]. Moreover, it is possible to optimize the use of the PAC's binding capacity by recirculation of PAC within the WWTP $[11,16]$. Several studies reported successful removal rates of $80 \%$ and more for many investigated MPs [11-14]. Furthermore, corresponding to the reduced MP concentrations in the effluent a significant reduction of toxicological effects in the form of improved invertebrate health, reduced genotoxicity and positive ecological changes were described by Peschke et al. [3], Stalter et al. [17] and Triebskorn et al. [14], respectively. Nevertheless, there is a drawback which is associated with the retention of PAC in the WWTP. The complete separation of PAC from the effluent appears to be challenging in order to prevent losses of MP-loaded PAC into the aquatic environment via the effluent $[15,18,19]$. Therefore, it is possible that adverse effects are associated with the introduction of MP-loaded PAC into the receiving waters with yet unknown ecological consequences. In previous studies, PAC from a WWTP did not cause negative effects to two filter-feeding invertebrates, the pelagic Daphnia magna [20] or benthic Corbicula sp. [21], which might be partly explained by sedimentation of PAC. It is expected that PAC from WWTP after entering receiving waters will mainly deposit in the sediment and therefore pose a risk to endo-benthic organisms rather than to pelagic or epi-benthic species. Accordingly, the question arises if sediment-dwelling organisms are negatively affected by the presence of MP-loaded PAC.

So far, only ecotoxicological studies on PAC in sediments in connection with sediment remediation by addition of unloaded activated carbon at contaminated sites are available. These studies showed that activated carbon can lead to a reduction in reproduction and growth in the sediment inhabiting annelid Lumbriculus variegatus [2224]. Field application of PAC was shown to have a general negative effect on the benthic community structure with reduction in species abundance and biomass [25, 26]. Moreover, it was discovered that particles smaller than $100 \mu \mathrm{m}$ are ingested by $L$. variegatus and that the powdered form of activated carbon was significantly more toxic than larger particles [27]. This underlines the need to assess possible adverse effects of MP-loaded PAC from WWTPs.

Therefore, the aim of the present study is to investigate possible harmful effects of MP-loaded PAC from WWTPs and to evaluate whether the release of MPloaded PAC poses an ecological risk for sedimentdwelling organisms. For this approach, sediment-water toxicity experiments according to OECD guideline 225 [28] were conducted in which individuals of $L$. variegatus were exposed to micropollutant-loaded PAC from a WWTP as compared to unloaded (native) and diclofenac-loaded PAC. L. variegatus was chosen because it plays an important role in aquatic ecosystems and it is frequently used in eco-toxicity testing for risk assessment [29-31]. Moreover, by using annelids several uptake routes are covered, i.e., via the sediment (ingestion and direct contact) and via the pore and overlaying water [32].

\section{Materials and methods \\ Test substances}

In order to examine possible adverse effects to the sediment-dwelling annelid $L$. variegatus, sediments were spiked with different types of PAC as shown in Table 1. In order to have an intermediate test substance between the unloaded PAC and the MP-loaded PAC from the WWTP, PAC was loaded with the well-known micropollutant diclofenac.

The activated carbon used for the experiments, PAC Norit ${ }^{\circledR}$ SAE Super [average particle size of $15 \mu \mathrm{m}$, total surface area (B.E.T.) of $1150 \mathrm{~m}^{2} / \mathrm{g}$, Cabot Corporation, USA], was supplied by the wastewater treatment plant in Dülmen, North Rhine-Westphalia, Germany (capacity of 55,000 population equivalents, operated by the Lippeverband). Acquisition of the MP-loaded PAC $\left(\mathrm{PAC}_{\mathrm{WWTP}}\right)$ as well as preparation of the other two PAC types is described in detail in Woermann and Sures [20]. Briefly, unloaded PAC was freeze-dried (Heto PowerDry LL3000, Thermo Electron Corporation) and either used as $\mathrm{PAC}_{\text {native }}$ in the exposure experiments or was loaded in the laboratory with diclofenac (DCF, Cayman Chemical Company, USA). For this approach, $1 \mathrm{~g}$ PAC was added

\begin{tabular}{ll}
$\begin{array}{l}\text { Table } 1 \text { Types of PAC used for exposure of } \\
\text { variegatus }\end{array}$ & Lumbriculus \\
\hline PAC type & Group name \\
\hline Micropollutant-loaded PAC from WWTP & PAC $_{\text {WWTP }}$ \\
Native, unloaded PAC & PAC $_{\text {native }}$ \\
Diclofenac-loaded PAC & PAC $_{\text {DCF }}$ \\
\hline
\end{tabular}


to $200 \mathrm{~mL}$ of a $0.4 \mathrm{~g} / \mathrm{L}$ DCF solution and agitated for $24 \mathrm{~h}$ which resulted in a loading of $80 \mathrm{mg}$ DCF per $\mathrm{g}$ PAC. The MP-loaded PAC (PAC ${ }_{\mathrm{W} W T \mathrm{~T}}$ ) was collected from the sedimentation basin of the treatment plant in Dülmen during 2 weeks in April 2017. PAC $\mathrm{DCF}_{\text {and }} \mathrm{PAC}_{\mathrm{WwWTP}}$ were freeze-dried as well to establish the same condition for each PAC type.

\section{Test organism}

The tests were conducted with the annelid Lumbriculus variegatus similar to the procedure described by Kontchou et al. [31]. Briefly, individuals of L. variegatus used to establish an own culture originally came from the Department of Aquatic Ecotoxicology at the Goethe University Frankfurt am Main, Germany. The culture was kept in a climate chamber at a temperature of $20 \pm 1{ }^{\circ} \mathrm{C}$ with a 16:8 h light:dark cycle. The worms were grown in $15 \mathrm{~L}$ glass aquaria containing a small layer of prewashed quartz sand (Baumit GmbH, Germany) as sediment and reconstituted water as described in the OECD guideline 225 [28]. Aquaria were constantly aerated and worms were fed twice a week with ground TetraMin flakes (Tetra $\mathrm{GmbH}$, Germany) following the renewal of overlying reconstituted water.

The sensitivity of the worms to harmful substances was validated using pentachlorophenol (PCP, 99\% pure, Sigma-Aldrich, USA) as recommended by the OECD guideline. Briefly, adult worms were removed from the culture and kept in clean reconstituted water for $24 \mathrm{~h}$. A stock solution of $5 \mathrm{mg} / \mathrm{L}$ PCP was prepared in reconstituted water and diluted to 2500, 1000, 500, 250, 100 and $50 \mu \mathrm{g} / \mathrm{L}$, respectively. The $\mathrm{pH}$ of the dilutions was adjusted to a value between 6.4 and 7 with $0.1 \mathrm{M} \mathrm{NaOH}$. Reconstituted water without PCP was used as the negative control. For each concentration, ten replicates were performed in $30 \mathrm{~mL}$ beakers comprising one adult worm. The experiment was run for $96 \mathrm{~h}$ under the same light and temperature conditions as the culture. After the termination of exposure, mortality of worms was recorded.

\section{General test design}

The exposure experiments were designed following the sediment-water toxicity test as described in the OECD guideline 225 [28]. For this approach, synchronized individuals of $L$. variegatus were exposed to the test substances spiked into the reconstituted sediment in a series of at seven concentrations along with a negative control. Each PAC compound was tested in concentrations of $0.5,1,1.5,2,3,4$ and $5 \mathrm{~g} / \mathrm{kg}$ dry weight $(\mathrm{dw})$. The control sediment was prepared without PAC addition. These test concentrations were chosen based on preliminary testing (data not shown) and in order to cover the $\mathrm{EC}_{50}$ as recommended by the OECD guideline. For each concentration and control, four replicates were prepared containing ten synchronized annelids resulting in 32 test beakers per exposure experiment.

\section{Synchronization}

Fourteen days prior to the start of the PAC exposure experiments, adult worms were synchronized as described in OECD 225 guideline [28]. After cutting the worms in two pieces, the posterior ends were used for the experiment while the anterior segments were returned to the culture. The posterior segments were cultured in a separate tank for 14 days for head development. They were kept under the same conditions as the normal culture, but without food supply and renewal of overlying water. Head development was evident after 7 to 8 days when worms burrowed into the sediment. After 14 days of growth, the worms were assumed to be of equal developmental stage and ready for exposure.

\section{Test sediment preparation}

Artificial sediment used in this study was prepared following OECD 225 guideline and contained quartz sand (size 0-1 mm, Baumit GmbH, Germany), kaolinite clay (VWR International, Belgium), peat (Floragard GmbH, Germany) and nettle powder (Folia urticae; Heinrich Klenk GmbH \& Co. KG, Germany) at a ratio of $75 \%$, $20 \%, 5 \%$ and $0.5 \%$ dry weight, respectively. Prior to use, the sand was properly washed with deionized water and dried at $70{ }^{\circ} \mathrm{C}$. A dry mass of $20 \mathrm{~g}$ air-dried peat $(<0.5 \mathrm{~mm}$ particle size) was weighed into an $800 \mathrm{~mL}$ glass beaker followed by addition of $200 \pm 20 \mathrm{~mL}$ deionized water (approximately $10 \mathrm{~mL}$ per gram of peat dry weight). The suspension was properly homogenized by stirring with a spatula and $\mathrm{pH}$ adjusted to between 5 and 5.5 using $\mathrm{CaCO}_{3}$ (98\%; Acros Organics, Belgium). The suspension was incubated for $48 \mathrm{~h}$ at room temperature on a shaker (Celltron, Infors HT, Switzerland) at a speed of 120 rounds per minute $(\mathrm{rpm})$ in order to establish a stable microbial content in the peat suspension. After $48 \mathrm{~h}$ incubation, the $\mathrm{pH}$ of the suspension was measured and adjusted with $\mathrm{CaCO}_{3}$ if required to a final value of $6 \pm 0.5$. The residual dry components, e.g., sand $(300 \mathrm{~g})$, clay $(80 \mathrm{~g})$ and nettle powder $(2 \mathrm{~g})$ were mixed together before adding the respective amounts of $\mathrm{PAC}_{\text {native, }}, \mathrm{PAC}_{\mathrm{DCF}}$ and $\mathrm{PAC}_{\mathrm{WWTP}}$. The peat suspension was then added to the dry mixture and the sediment was thoroughly homogenized. Formulated sediment samples were used immediately and no storage was required. The treatments were distributed into $300 \mathrm{~mL}$ glass beakers and reconstituted water was added to achieve a 1:4 sediment:water ratio. The setup was aerated with the help of glass Pasteur pipettes and equilibrated for $24 \mathrm{~h}$ at $20 \pm 1{ }^{\circ} \mathrm{C}$ with a light:dark circle of $16: 8 \mathrm{~h}$. 


\section{Sediment-water toxicity test}

The test was carried out in order to obtain data for the endpoints reproduction (increase in number of worms) and growth (increase in dry biomass) and were conducted according to the OECD guideline 225 [28]. Following the equilibration phase, water parameters (temperature, oxygen, $\mathrm{pH}$ and electrical conductivity) were checked and ten worms from the synchronized batch were carefully added to each exposure vessel. In order to obtain the initially inserted biomass, a sample of reference worms from the synchronized batch were collected and stored at $-80{ }^{\circ} \mathrm{C}$. The experiments were run for 28 days in a static exposure and water parameters were recorded every week. Moreover, the water level was refilled regularly with deionized water to compensate for losses due to evaporation and to keep the 1:4 sediment:water ratio. On the last day of exposure, water characteristics were recorded and the ammonium content was measured using the Aquamerck ${ }^{\circledR}$ Ammonium Test (Merck KGaA, Germany). Worms were carefully extracted, counted and frozen at $-80{ }^{\circ} \mathrm{C}$ for subsequent lyophilization (Heto PowerDry LL3000, Thermo Electron Corporation) and determination of dry weight (Labor AEG-220, Shimadzu, Japan). Additionally, at the end of the exposure photos were taken to visualize the moving activity of the test animals within the sediment.

\section{Statistical analysis}

The calculation and statistical analysis of the obtained data was performed with the program GraphPad Prism version 5.00 for Windows (GraphPad Software, San Diego California USA). The calculated effects of the endpoints reproduction and growth were plotted against the log-transformed exposure concentrations. A nonlinear regression analysis was carried out with a logistic fourparameter model with variable slope. In this analysis, the $\mathrm{EC}_{50}$ values (half maximum effective concentration) were calculated for reproduction and growth inhibition. Moreover, to investigate significant differences between control and exposed treatments Kruskal-Wallis test with the subsequent Dunn's multiple comparison test was applied. The significance level was set to $\alpha=0.05$.

\section{Results}

\section{Validity of the toxicity tests}

The performed reference tests with pentachlorophenol (PCP) in a $96 \mathrm{~h}$ water only exposure resulted in $\mathrm{LC}_{50}$ value of $198.5 \mu \mathrm{g} / \mathrm{L}$ which was within the range of previous studies $[33,34]$. The validity criteria according to OECD guideline 225 [28] for the tests were also met, as the average number of worms in the control increased by a factor of at least 1.8 except in the $\mathrm{PAC}_{\mathrm{DCF}}$ test group where the number of worms only increased by a factor of 1.35. The dissolved oxygen concentration during the test was always above $30 \%$ of air saturation value at test temperature and the $\mathrm{pH}$ of the overlying water was between 6 and 9. Also, the measured ammonium concentration in the overlying water at the end of the test was below $0.5 \mathrm{mg} / \mathrm{L}$ in all treatments. The obtained TOC value was $1.8 \pm 0.1 \%$ of the sediment dry weight.

\section{PAC exposure}

Following exposure to $\mathrm{PAC}_{\text {native }}$, strong effects on the reproduction of the worms could be detected (Fig. 1). In the two highest tested concentrations the worms did not reproduce at all and only the ten initially inserted worms were recovered. The Kruskal-Wallis test resulted in a significant difference $(H=26.2, p=0.0005)$ and the post hoc test revealed that the two highest concentrations were significantly different to the control group.

A similar trend was found in the experiments with PAC $_{\mathrm{DCF}}$, where not even all ten worms could be recovered in the two highest concentrations at the end of the exposure (Fig. 2). The Kruskal-Wallis test displayed a significant difference to the control $(H=20.2, p=0.006)$ which could not be confirmed by the post hoc test. In general, the worms reproduced less in the exposure with $\mathrm{PAC}_{\mathrm{DCF}}$ including the negative control. Therefore, the validity criterion for this test was not met. It is also obvious that the
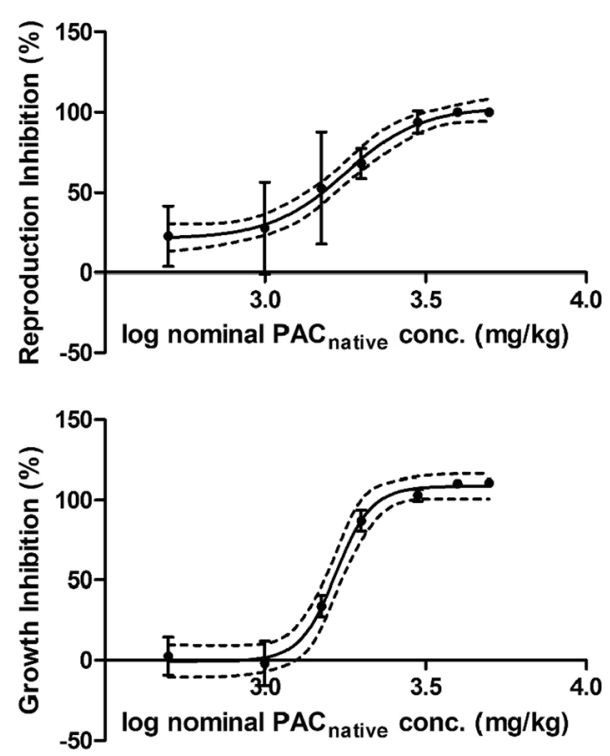

Fig. 1 Concentration-response curves for EC determination of reproduction (top) and growth (bottom) of Lumbriculus variegatus after 28 days of exposure with PAC $_{\text {native }}$ using the nominal concentrations; circle symbols represent means with standard deviations of the four beakers; dashed lines show 95\% confidence bands 

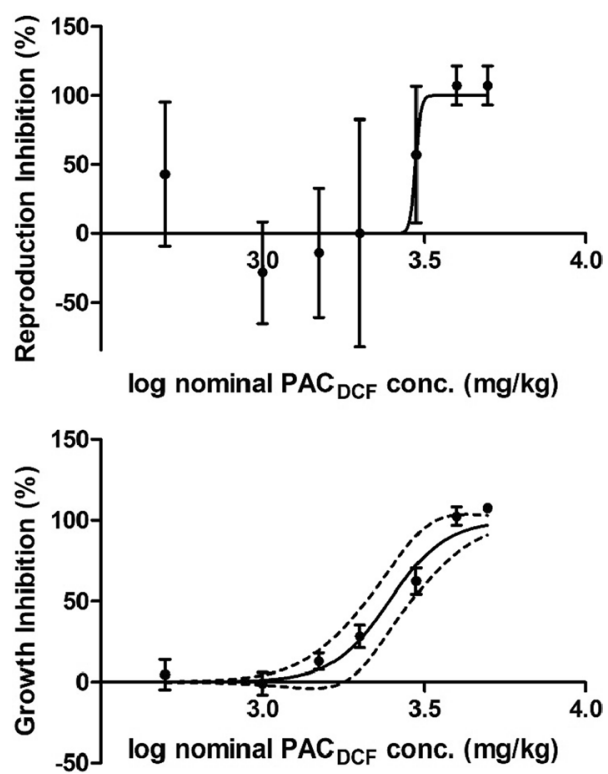

Fig. 2 Concentration-response curves for EC determination of reproduction (top) and growth (bottom) of Lumbriculus variegatus after 28 days of exposure with $P A C_{D C F}$ using the nominal concentrations; circle symbols represent means with standard deviations of the four beakers; dashed lines show 95\% confidence bands (could not be determined for the reproduction inhibition). This test was not valid according to the OECD guideline 225 regarding the reproduction in the control

standard deviations between the four replicates are comparatively high with regard to reproduction.

The worms that were exposed to PAC $_{\mathrm{WWTP}}$ did not show any negative effects with respect to reproduction (Fig. 3). The reproduction at the two highest concentrations was even higher than in the control, but not significantly $(H=7.26 ; p=0.402)$. However, the standard deviations were found to be high as well.

The concentration-response curves for the growth inhibition (based on dry weight gain) give a similar picture. For $\mathrm{PAC}_{\text {native }}$ and $\mathrm{PAC}_{\mathrm{DCF}}$ they show the typical sigmoid curve for concentration response relations (Figs. 1 and 2). The worms in these two groups show a very clear and significant effect concerning growth. According to the statistical analysis, significant differences to the control were detected for 4 and $5 \mathrm{~g} / \mathrm{kg} \mathrm{PAC}_{\text {native }}$ and for $5 \mathrm{~g} /$ kg PAC $_{\mathrm{DCF}}\left(\mathrm{PAC}_{\text {native }}: H=28.97, p=0.0002 ; \mathrm{PAC}_{\mathrm{DCF}}\right.$ : $H=28.59, p=0.0002)$. In these highest concentrations they did not only gain less weight than the worms from the control, but instead they even lost weight over the exposure period of 28 days when compared to the initial dry body weight. The tested individuals from the $\mathrm{PAC}_{\mathrm{WwWTP}}$ experiment did not show significant differences $(H=8.725, p=0.2732)$ compared to the control with regard to growth. Nevertheless, a trend is visible
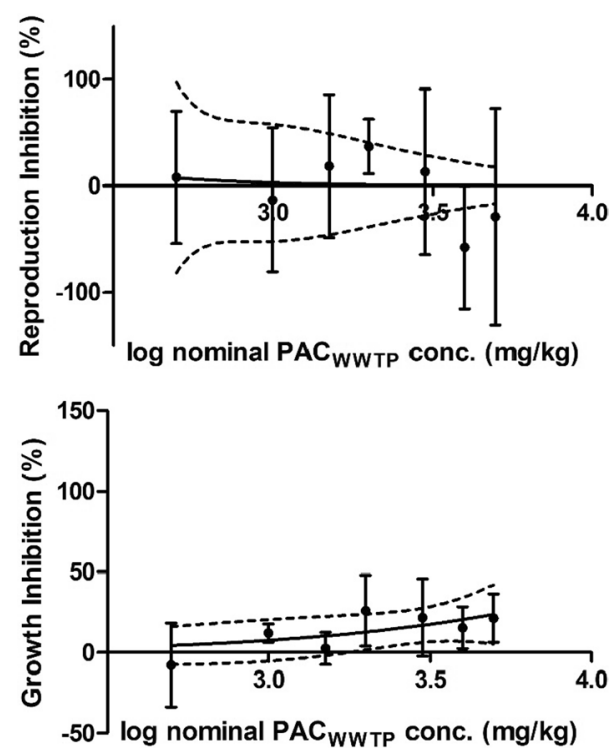

Fig. 3 Concentration-response curves for EC determination of reproduction (top) and growth (bottom) of Lumbriculus variegatus after 28 days of exposure with PAC $_{\text {WwTP }}$ using the nominal concentrations; circle symbols represent means with standard deviations of the four beakers; dashed lines show 95\% confidence bands

that the animals exposed to the higher concentrations grew less than the control (Fig. 3). It should also be noted that the standard deviations are particularly lower for the endpoint growth in contrast to the endpoint reproduction in all treatments. The corresponding $\mathrm{EC}_{50}$ values to all the graphs are given in Table 2.

The $\mathrm{EC}_{50}$ values confirm the patterns of the concentration response curves. PAC $_{\text {native }}$ showed the highest adverse effects as the lower values of $\mathrm{PAC}_{\text {native }}$ in comparison to $\mathrm{PAC}_{\mathrm{DCF}}$ indicate. Consequently, $\mathrm{PAC}_{\mathrm{DCF}}$ is less harmful and $\mathrm{PAC}_{\mathrm{WWWTP}}$ was not found to have any effects at all during the experiments. In general, EC values for the endpoint growth are slightly lower than for reproduction indicating a slight tendency towards higher

Table 2 Calculated $\mathrm{EC}_{50}$ values of reproduction and growth inhibition with corresponding 95\% confidence intervals (in parentheses) from the tests with Lumbriculus variegatus (please note that the values are given in $\mathrm{g} / \mathrm{kg}$ and not in $\mathrm{mg} / \mathrm{kg}$ as usual)

\begin{tabular}{lll}
\hline Test substance & $\begin{array}{l}\mathrm{EC}_{50} \text { reproduction } \\
\text { inhibition }\end{array}$ & $\mathrm{EC}_{\mathbf{5 0}}$ growth inhibition \\
\hline $\mathrm{PAC}$ native & $1.8 \mathrm{~g} / \mathrm{kg}(1.6$ to 2.0$)$ & $1.7 \mathrm{~g} / \mathrm{kg}(1.6$ to 1.8$)$ \\
$\mathrm{PAC}_{\text {DCF }}$ & $3.0 \mathrm{~g} / \mathrm{kg}$ (n.d.) & $2.5 \mathrm{~g} / \mathrm{kg}(2.1$ to 2.9$)$ \\
$\mathrm{PAC}_{\text {WWTP }}$ & n.d. & n.d. \\
\hline
\end{tabular}

n.d. not determinable 
sensitivity for the endpoint growth. Further to these evaluations, it was observed during the exposures with $\mathrm{PAC}_{\text {native }}$ and $\mathrm{PAC}_{\mathrm{DCF}}$ that the worms in the two highest concentrations did not burrow as deep as the animals in the other concentrations and the control (Fig. 4a, b). These animals resided only in the top layer of the sediment, whereas all other test animals burrowed through the whole sediment. The worms in the $\mathrm{PAC}_{\mathrm{WWTP}}$ exposures moved through the whole sediment even at the highest concentration of $5 \mathrm{~g} / \mathrm{kg}$ and no avoidance behavior was observed (Fig. 4c).

\section{Discussion}

The aim of the present study was to investigate possible negative effects of MP-loaded PAC to L. variegatus as a representative for sediment-dwelling organisms. With the chosen test-setup, chronic effects on reproduction and growth could be observed. Generally, it was noticed that growth was the more sensitive endpoint than reproduction and that the variation was also lower. This can be explained by the type of reproduction of $L$. variegatus which only reproduce asexually by fragmentation under laboratory conditions. After termination, some test vessels contained many small worms, whereas in other replicates fewer but larger individuals were found that had not yet fragmented at that time. The biomass between the replicates was more equal which explains the lower standard deviation for the endpoint growth (gain of biomass). Therefore, growth was found not only to be the more sensitive, but also the more robust endpoint in the present study. Moreover, these results indicate that the exposure period of 28 days may not have been long enough for the asexual reproduction to have been completed in all test beakers. Therefore, it is possible that the presence of PAC may have delayed the reproduction.

Regarding the toxicity of $\mathrm{PAC}_{\text {native }}, \mathrm{PAC}_{\mathrm{DCF}}$ and $\mathrm{PAC}_{\mathrm{WWWTP}}$, results of the present study are in line with the results from previous studies where exposure experiments were conducted with Daphnia magna [20] and Corbicula sp. [21]. Similarly, $\mathrm{PAC}_{\text {native }}$ induced the strongest effects, whereas $\mathrm{PAC}_{\mathrm{WWTP}}$ did not lead to any negative responses $[20,21]$. The evaluation of toxic mechanism was not within the scope of this study, however, possible explanations will be discussed briefly based on the obtained results and current knowledge. The strong effects, especially on growth, caused by $\mathrm{PAC}_{\text {native }}$ indicate either direct toxic effects or reduced nutrient availability during the exposure treatments. In studies conducted to assess toxicity of activated carbon amendments in sediments of contaminated sites, similar effects

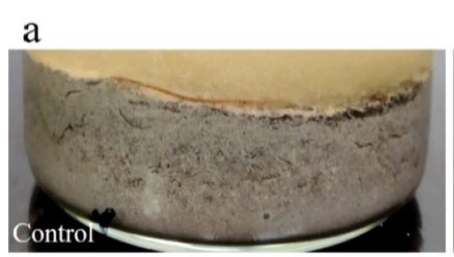

b
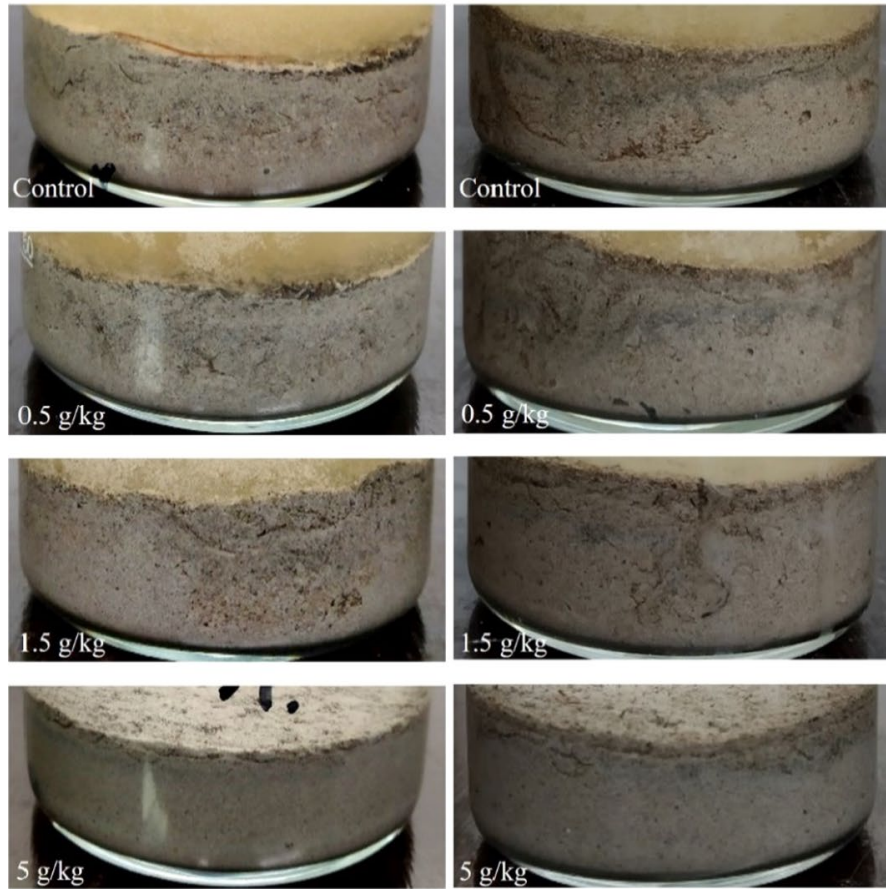
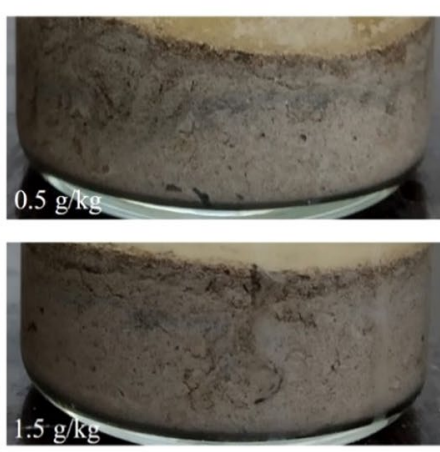

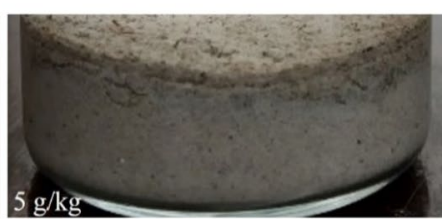

c
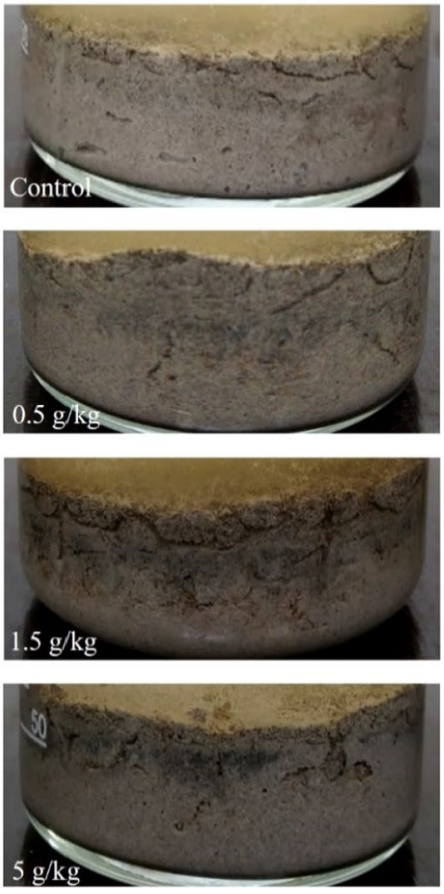

Fig. 4 Photo documentation of the test vessels from Lumbriculus variegatus exposure experiments after 28 days. Depicted are the test sediments of the negative control and three selected concentrations from exposures with a PAC native, $\mathbf{b}$ PAC $C_{D C F}$ and $\mathbf{c}$ PAC $C_{W w P}$ (the overlaying water phase is not shown due to reasons of space). Pictures were brightened in PowerPoint to increase visibility 
on L. variegatus were found. For example, Nybom et al. [27] detected a significant decrease in biomass already at a concentration of $0.05 \%$ PAC in artificial sediment $(\mathrm{dw})$. The $\mathrm{EC}_{50}$ value on biomass described by Nybom et al. [27] was $0.35 \%$ (corresponding to $3.5 \mathrm{~g} / \mathrm{kg}$ ) which is comparable to the $\mathrm{EC}_{50}$ values calculated for $\mathrm{PAC}_{\mathrm{DCF}}$ and $\mathrm{PAC}_{\text {native }}$ in the present study $(2.5 \mathrm{~g} / \mathrm{kg}$ and $1.7 \mathrm{~g} /$ $\mathrm{kg}$ on biomass, respectively). Furthermore, the egestion rate of the worms was investigated which is directly related to sediment ingestion and it was observed that the worms tried to avoid the AC exposure by a reduced or even terminated ingestion of the sediment. The same trends were reported by Abel et al. [22], Nybom et al. [35], Jonker et al. [24] and Han et al. [23]. In the present study, egestion and ingestion were not directly measured, but it was observed that the worms in the higher concentrated $\mathrm{PAC}_{\text {native }}$ and $\mathrm{PAC}_{\mathrm{DCF}}$ treatments were less active and stayed in the upper layer of the sediment (see Fig. 4a, b). Therefore, the reduced biomass can most likely be explained to a great extent by avoidance of sediment ingestion and an associated reduced food uptake. Conversely, it can be concluded that during the PAC $\mathrm{WWWTP}_{\mathrm{WW}}$ exposure, food uptake by the worms was not affected as they burrowed through the whole sediment and did not show avoidance behavior.

An explanation why PAC $_{\text {WwTP }}$ did not lead to any negative effects regarding the reproduction and growth nor any avoidance behavior might be due to the application and processing of PAC during its residence in the WWTP. Its use could possibly have smoothed the surface of the PAC and led to less sharp particles. In studies of Abel et al. [22] and Nybom et al. [35], it was found that the exposure with $\mathrm{AC}$ led to a decreased microvilli layer inside the gut wall in L. variegatus which can possibly be explained by damage due to sharp AC particles. This mechanical damage may as well have played a role in the observed avoidance behavior in the higher concentrations of $\mathrm{PAC}_{\text {native }}$ and $\mathrm{PAC}_{\mathrm{DCF}}$. Moreover, in the previous study conducted by Woermann and Sures [20] it was observed that $\mathrm{PAC}_{\text {native }}$ and $\mathrm{PAC}_{\mathrm{DCF}}$ did adhere to the cuticle of the daphnids, which led to obstruction of movements of D. magna. This could also be the case for $L$. variegatus and explain why the worms moved less in these treatments. Jonker et al. [24] suggested that AC could adsorb skin constituents (e.g., mucus) which could lead to the impairing effects.

Additionally, it is very likely that PAC adsorbs nutrients [36, 37] both externally from the sediment and also internally within the intestine of the annelids. Consequently, the high capacity of free binding sites of $\mathrm{PAC}_{\text {native }}$ would be responsible for the observed adverse effects. This would also explain why $\mathrm{PAC}_{\mathrm{WWTP}}$ did not show any inhibitory influence as the PAC was probably efficiently loaded during its application in the WWTP. This hypothesis is underlined by the fact that $\mathrm{PAC}_{\mathrm{DCF}}$ whose adsorption capacity has not been exploited was less harmful than $\mathrm{PAC}_{\text {native }}$. The minor negative tendency on the biomass that was detected in the higher concentrations with PAC $C_{\text {WWTP }}$ may be explained by a reduced food intake with increasing amounts of PAC $\mathrm{WWTP}_{\mathrm{W}}$ in the sediment and that $\mathrm{PAC}_{\mathrm{WWTP}}$ has no nutritional value. Generally, evaluation of detailed toxic mechanisms of the different PAC types applied was not the objective of this study, but should be addressed in future studies.

As a last point, it should be highlighted that the experimental setup was designed to test at a concentration range in which adverse effects will occur. Therefore, the tested concentrations are rather high and probably orders of magnitude higher than what would be expected to be reached in the aquatic environment. Still in the present study, no negative effects were induced by $\mathrm{PAC}_{\mathrm{WWTP}}$ in L. variegatus. The exact amount of PAC being released from WWTPs is to date still unknown as is the environmental fate and both topics should be the subject of future research. Up to now, leakages are considered to be small [38]. However, in standard operation also small amounts of PAC that are continuously released may settle in waters with low disturbance and will accumulate over time in sediments. Therefore, it is important to keep losses as low as possible through optimization efforts. Overall, it should be emphasized that the results of this study strongly support that PAC emissions from WWTPs are not associated with negative consequences for sediment-dwelling organisms.

\section{Conclusions}

The present study investigated possible adverse effects of native PAC, DCF-loaded PAC and MP-loaded PAC from a WWTP in a sediment-water test system with $L$. variegatus. The annelids exposed to $\mathrm{PAC}_{\text {native }}$ and $\mathrm{PAC}_{\mathrm{DCF}}$ showed a reduced gain in biomass and a reduced reproduction. Moreover, it was observed that $L$. variegatus avoided sediments spiked with high amounts of PAC. In contrast to that, L. variegatus did not show any negative effects when exposed to sediment spiked with $\mathrm{PAC}_{\mathrm{WWTP}}$, although very high concentrations were tested that would widely exceed expected values in the environment. Therefore, together with the results from previous studies with D. magna [20] and Corbicula sp. [21] the present study indicates that leakages from WWTPs are unlikely to pose a hazard for aquatic organisms. However, it is desirable to perform more research with more sensitive endpoints and longer exposure periods in order to ensure safe handling and avoid negative consequences for aquatic wildlife. In conclusion, the results of the present study are an important contribution for the risk 


\section{assessment of $\mathrm{PAC}_{\mathrm{WWWTP}}$ and give a good perspective for PAC as a safe removal option for MPs in WWTPs.}

\author{
Abbreviations \\ AC: Activated carbon; DCF: Diclofenac; dw: Dry weight; MPs: Micropollutants;

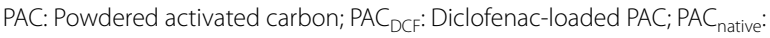 \\ Unloaded, native PAC; PAC wwTP: MP-loaded PAC from a WWTP; PCP: Pentachlo- \\ rophenol;WWTPs: Wastewater treatment plants.

\section{Acknowledgements} \\ This research was conducted as part of the collaborative project "Den \\ Spurenstoffen auf der Spur" (DSADS 3). The project was funded by Bezirksr- \\ egierung Münster. We are grateful to Jörg Oehlmann (Department of Aquatic \\ Ecotoxicology, Goethe University Frankfurt am Main, Germany) for providing \\ individuals of Lumbriculus variegatus, which were used to establish an own \\ culture in the Aquatic Ecology group at UDE.
}

\section{Authors' contributions}

BS, JK and MW designed the experimental setup. The exposure experiment and data analyses were carried out by MW and JK to equal parts. MW and JK wrote the draft manuscript including the preparation of all pictures and tables. Final reviewing and editing of the manuscript was done by BS and MW amended the manuscript accordingly. All authors read and approved the final manuscript.

\section{Funding}

Open Access funding enabled and organized by Projekt DEAL. The present study was conducted as part of the project "Den Spurenstoffen auf der Spur" (DSADS 3) which was funded by Bezirksregierung Münster.

\section{Availability of data and materials}

Material and data are described in the main article. The datasets used and/ or analyzed during the current study are available from the corresponding author on reasonable request.

\section{Declarations}

\section{Ethics approval and consent to participate}

Not applicable.

\section{Consent for publication}

Not applicable.

\section{Competing interests}

The authors declare that they have no competing interests.

Received: 7 May 2021 Accepted: 27 July 2021

Published online: 06 August 2021

\section{References}

1. Daughton CG, Ternes TA (1999) Pharmaceuticals and personal care products in the environment: agents of subtle change? Environ Health Perspect 107:907-938. https://doi.org/10.1289/ehp.99107s6907

2. Escher BI, Bramaz N, Quayle P et al (2008) Monitoring of the ecotoxicological hazard potential by polar organic micropollutants in sewage treatment plants and surface waters using a mode-of-action based test battery. J Environ Monit 10:622-631. https://doi.org/10.1039/b800951a

3. Peschke K, Capowiez Y, Köhler H-R et al (2019) Impact of a wastewater treatment plant upgrade on amphipods and other macroinvertebrates: individual and community responses. Front Environ Sci 7:1-13. https:// doi.org/10.3389/fenvs.2019.00064

4. Luo Y, Guo W, Ngo HH et al (2014) A review on the occurrence of micropollutants in the aquatic environment and their fate and removal during wastewater treatment. Sci Total Environ 473-474:619-641

5. Kasprzyk-Hordern B, Dinsdale RM, Guwy AJ (2009) The removal of pharmaceuticals, personal care products, endocrine disruptors and illicit drugs during wastewater treatment and its impact on the quality of receiving waters. Water Res 43:363-380. https://doi.org/10.1016/J.WATRES.2008.10. 047

6. Joss A, Siegrist $H$, Ternes TA (2008) Are we about to upgrade wastewater treatment for removing organic micropollutants? Water Sci Technol 57:251-255. https://doi.org/10.2166/wst.2008.825

7. Altmann J, Ruhl AS, Zietzschmann F, Jekel M (2014) Direct comparison of ozonation and adsorption onto powdered activated carbon for micropollutant removal in advanced wastewater treatment. Water Res 55:185-193. https://doi.org/10.1016/J.WATRES.2014.02.025

8. Escher Bl, Fenner K (2011) Recent advances in environmental risk assessment of transformation products. Environ Sci Technol 45:3835-3847. https://doi.org/10.1021/es1030799

9. Rothe LE, Botha TL, Feld CK, Weyand M, Zimmermann S, Smit N, Wepener $V$, Sures B (2021) Effects of conventionally-treated and ozonated wastewater on mortality, physiology, body length, and behavior of embryonic and larval zebrafish (Danio rerio). Environ Pollut 286:117241

10. Kovalova L, Siegrist H, von Gunten $U$ et al (2013) Elimination of micropollutants during post-treatment of hospital wastewater with powdered activated carbon, ozone, and UV. Environ Sci Technol 47:7899-7908. https://doi.org/10.1021/es400708w

11. Boehler M, Zwickenpflug B, Hollender J et al (2012) Removal of micropollutants in municipal wastewater treatment plants by powder-activated carbon. Water Sci Technol 66:2115-2121. https://doi.org/10.2166/wst. 2012.353

12. Kårelid V, Larsson G, Björlenius B (2017) Pilot-scale removal of pharmaceuticals in municipal wastewater: comparison of granular and powdered activated carbon treatment at three wastewater treatment plants. J Environ Manag 193:491-502. https://doi.org/10.1016/J.JENVMAN.2017.02. 042

13. Mailler R, Gasperi J, Coquet Y et al (2015) Study of a large scale powdered activated carbon pilot: removals of a wide range of emerging and priority micropollutants from wastewater treatment plant effluents. Water Res 72:315-330. https://doi.org/10.1016/j.watres.2014.10.047

14. Triebskorn R, Blaha L, Gallert C et al (2019) Freshwater ecosystems profit from activated carbon-based wastewater treatment across various levels of biological organisation in a short timeframe. Environ Sci Eur 31:85. https://doi.org/10.1186/s12302-019-0267-0

15. Margot J, Kienle C, Magnet A et al (2013) Treatment of micropollutants in municipal wastewater: ozone or powdered activated carbon? Sci Total Environ 461-462:480-498. https://doi.org/10.1016/j.scitotenv.2013.05.034

16. Meinel F, Zietzschmann F, Ruhl AS et al (2016) The benefits of powdered activated carbon recirculation for micropollutant removal in advanced wastewater treatment. Water Res 91:97-103. https://doi.org/10.1016/j. watres.2016.01.009

17. Stalter D, Magdeburg A, Oehlmann J (2010) Comparative toxicity assessment of ozone and activated carbon treated sewage effluents using an in vivo test battery. Water Res 44:2610-2620. https://doi.org/10.1016/j. watres.2010.01.023

18. Altmann J, Sperlich A, Jekel M (2015) Integrating organic micropollutant removal into tertiary filtration: combining PAC adsorption with advanced phosphorus removal. Water Res 84:58-65. https://doi.org/10.1016/j. watres.2015.07.023

19. Krahnstöver T, Wintgens $T$ (2018) Separating powdered activated carbon (PAC) from wastewater-technical process options and assessment of removal efficiency. J Environ Chem Eng 6:5744-5762. https://doi.org/10. 1016/j.jece.2018.09.001

20. Woermann M, Sures B (2020) Ecotoxicological effects of micropollutantloaded powdered activated carbon emitted from wastewater treatment plants on Daphnia magna. Sci Total Environ 746:141104. https://doi.org/ 10.1016/j.scitotenv.2020.141104

21. Woermann M, Zimmermann S, Sures B (2020) Is micropollutant-loaded powdered activated carbon from a wastewater treatment plant toxic to the bivalve Corbicula sp. Environ Sci Eur. https://doi.org/10.1186/ s12302-020-00430-6

22. Abel S, Nybom I, Mäenpää K et al (2017) Mixing and capping techniques for activated carbon based sediment remediation-efficiency and adverse effects for Lumbriculus variegatus. Water Res 114:104-112. https:// doi.org/10.1016/j.watres.2017.02.025

23. Han Z, Sani B, Akkanen J et al (2015) A critical evaluation of magnetic activated carbon's potential for the remediation of sediment impacted by 
polycyclic aromatic hydrocarbons. J Hazard Mater 286:41-47. https://doi. org/10.1016/j.jhazmat.2014.12.030

24. Jonker MTO, Suijkerbuijk MPW, Schmitt H, Sinnige TL (2009) Ecotoxicological effects of activated carbon addition to sediments. Environ Sci Technol 43:5959-5966. https://doi.org/10.1021/es900541p

25. Cornelissen G, Elmquist Kruså M, Breedveld GD et al (2011) Remediation of contaminated marine sediment using thin-layer capping with activated carbon - a field experiment in Trondheim harbor, Norway. Environ Sci Technol 45:6110-6116. https://doi.org/10.1021/es2011397

26. Samuelsson GS, Raymond C, Agrenius S et al (2017) Response of marine benthic fauna to thin-layer capping with activated carbon in a large-scale field experiment in the Grenland fjords, Norway. Environ Sci Pollut Res 24:14218-14233. https://doi.org/10.1007/s11356-017-8851-6

27. Nybom I, Werner D, Leppänen MT et al (2012) Responses of Lumbriculus variegatus to activated carbon amendments in uncontaminated sediments. Environ Sci Technol 46:12895-12903. https://doi.org/10.1021/ es303430j

28. OECD (2007) Test No. 225: sediment-water Lumbriculus toxicity test using spiked sediment, OECD Guidelines for the Testing of Chemicals, Section 2. OECD Publishing, Paris. https://doi.org/10.1787/9789264067 356-en

29. Chapman PM (2001) Utility and relevance of aquatic oligochaetes in ecological risk assessment. In: Rodriguez P, Verdonschot PFM (eds) Aquatic oligochaete biology VIII. Developments in hydrobiology, vol 158. Springer, Dordrecht, pp 149-169

30. Phipps GL, Ankley GT, Benoit DA, Mattson VR (1993) Use of the aquatic oligochaete Lumbriculus variegatus for assessing the toxicity and bioaccumulation of sediment-associated contaminants. Environ Toxicol Chem 12:269-279. https://doi.org/10.1002/etc.5620120210

31. Kontchou JA, Nachev M, Sures B (2021) Ecotoxicological effects of trafficrelated metal sediment pollution in Lumbriculus variegatus and Gammarus sp. Environ Pollut 268:115884. https://doi.org/10.1016/j.envpol. 2020.115884

32. Conrad AU, Comber SD, Simkiss K (2000) New method for the assessment of contaminant uptake routes in the oligochaete Lumbriculus variegatus.
Bull Environ Contam Toxicol 65:16-21. https://doi.org/10.1007/s0012 800088

33. Hickey CW, Martin ML (1995) Relative sensitivity of five benthic invertebrate species to reference toxicants and resin-acid contaminated sediments. Environ Toxicol Chem 14:1401-1409. https://doi.org/10.1002/etc. 5620140817

34. Nikkilä A, Halme A, Kukkonen JVK (2003) Toxicokinetics, toxicity and lethal body residues of two chlorophenols in the oligochaete worm, LumbricuIus variegatus, in different sediments. Chemosphere 51:35-46. https://doi. org/10.1016/S0045-6535(02)00791-9

35. Nybom I, Waissi-Leinonen G, Mäenpää K et al (2015) Effects of activated carbon ageing in three PCB contaminated sediments: sorption efficiency and secondary effects on Lumbriculus variegatus. Water Res 85:413-421. https://doi.org/10.1016/j.watres.2015.08.044

36. Schreiber B, Brinkmann T, Schmalz V, Worch E (2005) Adsorption of dissolved organic matter onto activated carbon-the influence of temperature, absorption wavelength, and molecular size. Water Res 39:3449-3456. https://doi.org/10.1016/j.watres.2005.05.050

37. Jonker MTO, Hoenderboom AM, Koelmans AA (2004) Effects of sedimentary sootlike materials on bioaccumulation and sorption of polychlorinated biphenyls. Environ Toxicol Chem 23:2563-2570. https://doi.org/10. 1897/03-351

38. Krahnstöver T, Zenker A, Baggenstos M et al (2019) Characterizing solids retention, head loss development and micropollutant removal in the case of direct powdered activated carbon dosage upstream of deep bed filtration. Environ Sci Water Res Technol 5:2172-2181. https://doi.org/10. 1039/c9ew00658c

\section{Publisher's Note}

Springer Nature remains neutral with regard to jurisdictional claims in published maps and institutional affiliations.

\section{Submit your manuscript to a SpringerOpen ${ }^{\circ}$ journal and benefit from:}

- Convenient online submission

- Rigorous peer review

- Open access: articles freely available online

- High visibility within the field

- Retaining the copyright to your article

Submit your next manuscript at $\boldsymbol{\nabla}$ springeropen.com 